\section{Knowledge and global health: reducing the burden of non-communicable diseases using physical activity}

\author{
Steve Aspinall, ${ }^{1}$ Allan Munro ${ }^{2}$
}

In this BASRaT guided issue of BJSM, we look at how we can support healthy lifestyles for our patients, athletes and also to improve public health (figure 1). In its global action plan on physical activity (PA; 2018-2030) the WHO sets out four strategic objectives for a healthier world; to create active societies, active people, active environments and active systems. Achieving these goals will help prevent and treat non-communicable diseases (NCDs), including heart disease, stroke, diabetes and breast and colon cancer. ${ }^{1}$

Increasing PA improves the key disease risk factors hypertension and obesity as well as having a positive effect on mental health, delaying the onset of dementia and improving both quality of life and wellbeing. ${ }^{1}$ By helping our patients become more active Sports Rehabilitators can play a key role in reducing the social and economic burden of NCDs across the world.

We clinicians know we want people to be more active, we know the potential rewards for both individuals and society more generally but how do we achieve these goals? Knowledge informs clinical practice and we need to apply that to find opportunities for adding PA to peoples' lives. This is supported in the UK by numerous campaigns and initiatives, including the Active 10, couch to $5 \mathrm{k}$, The Daily Mile, This Girl Can and the Royal College of General Practitioners Parkrun Practice initiative. PA is a cost-effective intervention, ${ }^{2}$ but to use it we need appropriate knowledge. This BASRaT-led issue of the BJSM will help you not only build your knowledge base in this area but also help you to apply it clinically.

\section{WHAT'S NEW IN THIS BASRAT GUIDED ISSUE?}

The UK's Chief Medical Officer guidelines recommend at least $75 \mathrm{~min}$ of vigorous or $150 \mathrm{~min}$ of moderate intensity

${ }^{1}$ School of Health Sciences, University of Salford, Salford, UK

${ }^{2}$ School of Health, Sport and Rehabilitation Sciences, University of Salford, Salford, UK

Correspondence to Steve Aspinall, School of Health Sciences, University of Salford, Salford M6 6PU, UK; S.J.Aspinall@salford.ac.uk

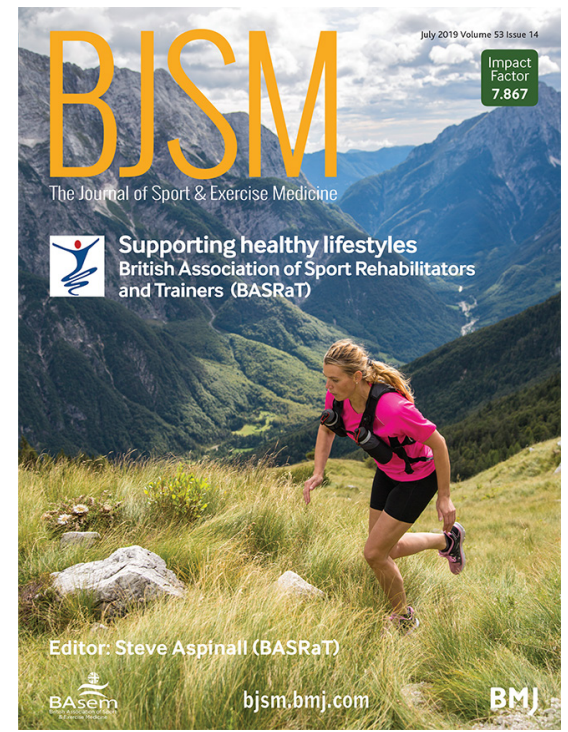

Figure 1 Supporting healthy lifestyles - what can we do to make a difference?

cardiorespiratory exercise each week. However, when even terms like exercise or sport can have a negative effect on a patients' uptake of activity, those targets can seem out of reach for many and so we focus on pragmatic alternatives to increase PA. One simple way to do this is to integrate activity into our daily lives, with active transport being a popular example. Is this enough to make a real difference to health?

In a systematic review and meta-analysis, Solveig Nordengen and her Scandinavian colleagues provide an insight into the health benefits of cycling as a form of transport, providing strong evidence that even in relatively low doses cycling provides a protective effect against cardiovascular disease (CVD) (see page 870 ). On a related topic, another Nordic leader, Professor Ulf Ekelund and colleagues systematic review and harmonised meta-analysis explore the associations of sedentary behaviour with CVD and cancer mortality and whether they differ by activity level. We already know that high levels of unbroken sedentary behaviour are associated with abnormal glucose metabolism, cardiometabolic morbidity and overall mortality, ${ }^{23}$ but this new study adds further detail about the PA dose needed to reduce these risks. This is supported by editorials from Sydney's Professor Emmanuel Stamatakis and colleagues (see page 853) and US professors Hannah Arem and Charles Matthews (see page 854), with clear messages not only about reducing sitting time but also increasing movement.

In an exciting new update in this field, Associate Professor Huseyin Naci from the London School of Economics and his renowned coauthor share the first network meta-analysis on the comparative effectiveness of exercise and medication on systolic blood pressure (SBP). Different hypertension cut-offs are used and the SBP lowering effects of exercise at each level are described; this is an important distinction as for the adults in the highest cut-offs, exercise reduced SBP to a similar level as medication, making it a more valuable addition to existing pharmacological management than widely thought (see page 859 ).

Further highlighting the importance of PA, Qian Lao Xiang and colleagues' prospective cohort study followed 44000 Chinese adults for 18 years and found that leisure-time PA was associated with a decreased onset of diabetes in adults with impaired fasting glucose (see page 895 ). In their editorial, Canada's Professor Stuart Phillips partnered with the Mayo Clinic's Michael Joyner to caution that there can be misunderstanding of the phrase 'you can't outrun a bad diet'. They vociferously reinforce the multitude of health benefits of increasing PA (see page 854). If you also want an evidence based consensus statement from some of the worldsleading authorities about PA and ageing, then Denmark's Professor Jens Bangsbo and colleagues' Copenhagen Consensus Statement, highlight the benefits for both brain health and cognitive function as well as functional capacity and health (see page 856).

The editorial by Mervyn Travers and colleagues reminds us that we need to pay attention to the comparisons being made in research studies and what it means for clinical practice; in this case low back pain, but it could apply to any number of complex areas (see page 847). In addition to the appropriate interpretation of the research, there are a number of barriers to us prescribing PA, with one of the most common being pain. In their valuable narrative non-systematic review, Benjamin Smith and colleagues provide a clear framework and rationale for prescribing exercise for patients in pain that can improve outcomes and also challenge patients to think differently about tissue 


\section{Warm up}

damage and pain (see page 907). Linked into this is the infographic by Ronaldo Briani and colleagues ably illustrating that exercise therapy improves health-related and knee-related quality of life for individuals with knee osteoarthritis (see page 903).

\section{FRIENDLY REMINDER ABOUT BASRAT}

BASRaT is the UK regulator for Sport and Exercise Rehabilitators and an advocate of the multidisciplinary healthcare team and improving public health by lifestyle and PA. BASRaT guides Sport Rehabilitators on all aspects of their role and responsibilities, ensuring public protection, professional competency and continued professional development.

The BASRaT register of Sport Rehabilitators has been approved as an accredited register by the Professional Standards Authority for Health and Social Care. For more detail please visit us at www.basrat. org and don't hesitate to contact us if you would like to work collaboratively on public health projects.

Funding The authors have not declared a specific grant for this research from any funding agency in the public, commercial or not-for-profit sectors.

Competing interests None declared.

Patient consent for publication Not required.

Provenance and peer review Commissioned; internally peer reviewed.

C Author(s) (or their employer(s)) 2019. No commercial re-use. See rights and permissions. Published by BMJ.

D Check for updates
To cite Aspinall S, Munro A. Br J Sports Med 2019;53:845-846.

Accepted 22 May 2019

Br J Sports Med 2019;53:845-846. doi:10.1136/bjsports-2019-101105

\section{REFERENCES}

1 WHO. Global action plan on physical activity 2018-2030: more active people for a healthier world. Licence: CC BY-NC-SA 3.0 IGO. Geneva World Health Organization; 2018.

2 WHO. Tackling NCDs: 'Best buys' and other recommended interventions for the prevention and control of noncommunicable disease. Geneva World Health Organization; 2017.

3 Owen N, Healy GN, Matthews CE, et al. Too much sitting: the population health science of sedentary behavior. Exerc Sport Sci Rev 2010;38:105-13. 